\title{
Proteomic analysis of cortical neuronal cultures treated with poly-arginine peptide- 18 (R18) and exposed to glutamic acid excitotoxicity
}

\author{
Gabriella MacDougall ${ }^{3,4^{*}}$ D, Ryan S. Anderton ${ }^{1,3,4}$, Frank L. Mastaglia ${ }^{1,3}$, Neville W. Knuckey ${ }^{1,2,3}$ and \\ Bruno P. Meloni ${ }^{1,2,3}$
}

\begin{abstract}
Poly-arginine peptide-18 (R18) has recently emerged as a highly effective neuroprotective agent in experimental stroke models, and is particularly efficacious in protecting cortical neurons against glutamic acid excitotoxicity. While we have previously demonstrated that R18 can reduce excitotoxicity-induced neuronal calcium influx, other molecular events associated with R18 neuroprotection are yet to investigated. Therefore, in this study we were particularly interested in protein expression changes in R18 treated neurons subjected to excitotoxicity. Proteomic analysis was used to compare protein expression patterns in primary cortical neuronal cultures subjected to: (i) R18-treatment alone (R18); (ii) glutamic acid excitotoxic injury (Glut); (iii) R18-treatment and glutamic acid injury (R18 + Glut); (iv) no treatment (Cont). Whole cell lysates were harvested $24 \mathrm{~h}$ post-injury and subjected to quantitative proteomic analysis (iTRAQ), coupled with liquid chromatography-tandem mass spectrometry (LC-MS/ MS) and subsequent bioinformatic analysis of differentially expressed proteins (DEPS).

Relative to control cultures, R18, Glut, and R18 + Glut treatment resulted in the detection of 5, 95 and 14 DEPs respectively. Compared to Glut alone, R18 + Glut revealed 98 DEPs, including 73 proteins whose expression was also altered by treatment with Glut and/or R18 alone, as well as 25 other uniquely regulated proteins. R18 treatment reversed the up- or down-regulation of all 73 Glut-associated DEPs, which included proteins involved in mitochondrial integrity, ATP generation, mRNA processing and protein translation. Analysis of protein-protein interactions of the 73 DEPs showed they were primarily associated with mitochondrial respiration, proteasome activity and protein synthesis, transmembrane trafficking, axonal growth and neuronal differentiation, and carbohydrate metabolism. Identified protein pathways associated with proteostasis and energy metabolism, and with pathways involved in neurodegeneration.

Collectively, the findings indicate that R18 neuroprotection following excitotoxicity is associated with preservation of neuronal protein profiles, and differential protein expression that assists in maintaining mitochondrial function and energy production, protein homeostasis, and membrane trafficking.
\end{abstract}

Keywords: Poly-arginine-18 (R18), iTRAQ proteomics, Neuroprotection, Mito-protection, Excitotoxicity, Stroke

\footnotetext{
* Correspondence: gabriella01@iinet.net.au

${ }^{3}$ Perron Institute for Neurological and Translational Sciences, QEII Medical Centre, Ground Floor, RR Block, 8 Verdun St, Nedlands, Western Australia 6009, Australia

${ }^{4}$ School of Heath Sciences and Institute for Health Research, The University Notre Dame, Fremantle, Western Australia, Australia

Full list of author information is available at the end of the article
}

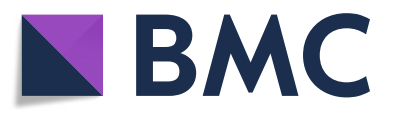

(c) The Author(s). 2019 Open Access This article is distributed under the terms of the Creative Commons Attribution 4.0 International License (http://creativecommons.org/licenses/by/4.0/), which permits unrestricted use, distribution, and reproduction in any medium, provided you give appropriate credit to the original author(s) and the source, provide a link to the Creative Commons license, and indicate if changes were made. The Creative Commons Public Domain Dedication waiver (http://creativecommons.org/publicdomain/zero/1.0/) applies to the data made available in this article, unless otherwise stated. 


\section{Introduction}

A major pathophysiological mechanism responsible for ischaemic stroke injury is excitotoxicity, which is trigged by the excessive release of the excitatory neurotransmitter glutamic acid in response to reduced cerebral blood flow and compromised ATP synthesis. Excitotoxicity initiates a range of forward-feeding biochemical events known as the 'ischaemic cascade', which if not inhibited eventually lead to neuronal death and cerebral infarction [1]. Furthermore, as glutamic acid is the most prominent excitatory neurotransmitter in the CNS [2], the detrimental effects of glutamic acid excitotoxicity also play a role in other acute brain disorders such as traumatic brain injury and epilepsy, as well as chronic neurodegenerative disorders, such as Alzheimer's disease (AD) [3, 4], Huntington's disease (HD) $[5,6]$, Parkinson's disease (PD) $[7,8]$, and amyotrophic lateral sclerosis (ALS) $[9,10]$.

Despite ongoing research, neuroprotective therapies for acute brain injuries and other neurodegenerative disorders are either not available or are extremely limited with modest efficacy. Recent studies in our laboratory have identified cationic arginine-rich peptides (CARPs), which include poly-arginine peptides, as a novel class of neuroprotective agents. In particular, we have demonstrated that poly-arginine-18 (R18, 18-mer of arginine) is neuroprotective in in vitro neuronal excitotoxicity models and in vivo in rodent models of stroke [11-18], hypoxic-ischaemic encephalopathy (HIE) [19], and traumatic brain injury (TBI) [20, 21].

Given the neuroprotective properties of R18, it is imperative that the molecular pathways that underlie its neuroprotective action are fully elucidated in order to gauge its therapeutic potential. While we have previously demonstrated that R18 has the capacity to reduce glutamic acid-induced excitotoxic neuronal death and intracellular calcium influx, and reduce neuronal NMDA receptor levels [22], CARPs also have cell-penetrating properties and can target mitochondria [23]. Therefore, it is likely that R18 and other CARPs have additional intracellular neuroprotective mechanisms of action. In addition, it is also important to examine the ability of R18 to preserve intracellular protein expression and biochemical pathways following a neurodamaging insult. As such, in this study we performed iTRAQ proteomics and bioinformatic analysis (Fig. 1) of protein cell lysates collected from primary cortical neuronal cultures subjected to glutamic acid excitotoxicity with and without treatment with R18.

\section{Methods}

\section{Peptides}

Poly-arginine-18 (R18; H-RRRRRRRRRRRRRRRRRR$\mathrm{OH}$ ) was synthesized by Mimotopes (Australia) and purified to $98 \%$ by HPLC. Peptides were prepared as
$500 \mu \mathrm{M}$ stocks in Baxter water (Australia) and stored at $-20^{\circ} \mathrm{C}$ prior to use.

\section{Primary cortical neuronal cultures}

Cortical neuronal tissue was extracted from E18 Sprague-Dawley rat embryos, dissociated, resuspended in Neurobasal/2\% B27 supplement (B27) and seeded at approximately 55,000 cells/well into 96-well plates (Nunc, Australia), pre-coated with poly-lysine (SigmaAldrich Australia) as previously described [24]. Plates were maintained at $37^{\circ} \mathrm{C}$ in a $\mathrm{CO}_{2}$ incubator $(95 \%$ air balance, $98 \%$ humidity, $5 \% \mathrm{CO}_{2}$ ) until use on day in vitro 10 , when cultures routinely comprise $>97 \%$ neurons and 1-3\% astrocytes. Approval for the use of E18 SpragueDawley rat embryos for isolation of cortical tissue was obtained by the University of Western Australia Animal Ethics Committee (RA/3/100/1432).

Glutamic acid excitotoxicity model and assessment of cell viability

Cortical neuronal cultures were subjected to glutamic acid excitotoxicity and R18 treatment as previously described [22]. R18 treatment consisted of adding the peptide to culture wells $10 \mathrm{~min}$ prior to glutamic acid (L-glutamic acid; Sigma-Aldrich) exposure by removing media and adding $50 \mu \mathrm{L}$ of Minimal Essential Media (MEM) $/ 2 \%$ B27 containing peptide $(2 \mu \mathrm{M})$. To induce excitotoxicity, $50 \mu \mathrm{L}$ of MEM/2\% B27 containing glutamic acid $(200 \mu \mathrm{M}$; final concentration $100 \mu \mathrm{M}$ ) was added to the culture wells and incubated at $37^{\circ} \mathrm{C}$ in the $\mathrm{CO}_{2}$ incubator for $5 \mathrm{~min}$ (note: peptide concentration reduced to $1 \mu \mathrm{M}$ during this step). Following the 5-min exposure, media was replaced with $100 \mu \mathrm{L}$ of MEM/2\% B27 and cultures incubated for a further $24 \mathrm{~h}$ at $37^{\circ} \mathrm{C}$ in the $\mathrm{CO}_{2}$ incubator. Untreated controls with or without glutamic acid treatment underwent the same incubation steps and media additions.

At $24 \mathrm{~h}$ post-injury, cell viability was assessed qualitatively by light microscopy, and quantitatively using the CellTiter 96 Aqueous Cell Proliferation MTS assay (Promega, Australia), which determines metabolic capacity of cells through the reduction of the tetrazolium salt (MTS), forming a brown formazan salt that is measured spectrophotometrically at $490 \mathrm{~nm}$.

\section{Protein extraction}

At $24 \mathrm{~h}$ post-injury, cells were lysed with $20 \mu \mathrm{L} /$ well of RIPA buffer (mM: $150 \mathrm{NaCl}, 5$ EDTA, 50 Tris; \%: 1.0 NP-40, 0.5 sodium deoxycholate, 0.1 SDS; pH 8.0) containing protease and phosphatase inhibitor cocktail (Roche Applied Science, Australia). Cell lysates from 8 wells within the same plate were pooled, and this was repeated four times with independent neuronal cultures. 


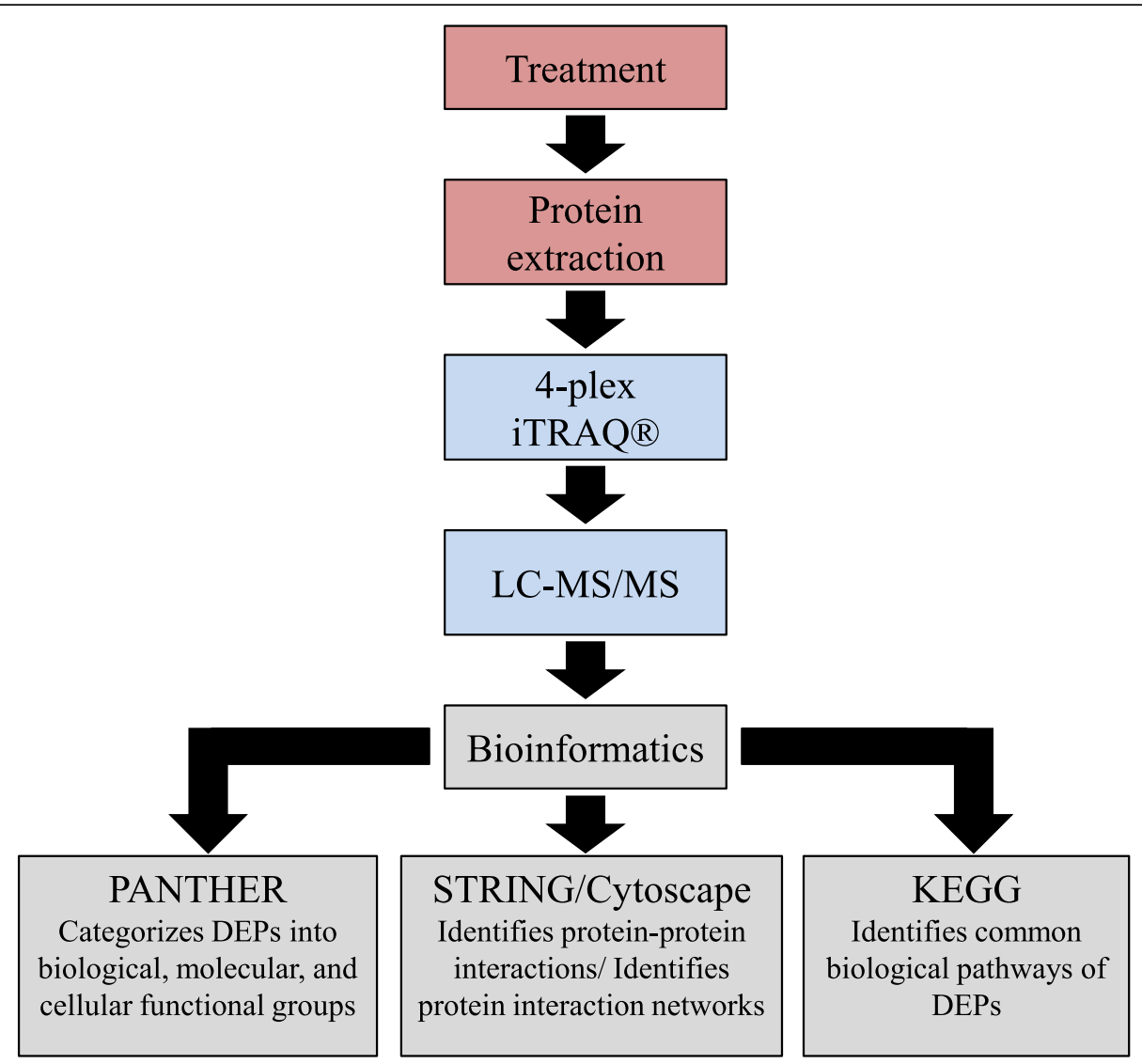

Fig. 1 Summary diagram of experimental flow, with the three key processes highlighted by different colours. These broadly include the initial cell treatment and protein collection (red); protein processing, purification, iTRAQ labelling, and quantification for each sample (blue); and analysis of bioinformatics data (grey). DEPs = differentially expressed proteins; LC-MS/MS = liquid chromatography-tandem mass spectrometry

Lysates were clarified by centrifugation at $14,000 \mathrm{~g}$ for 5 min at $4{ }^{\circ} \mathrm{C}$, and protein concentration determined via Bradford's assay (Bio-Rad). Aliquots $(3.5 \mathrm{mg} / \mathrm{mL})$ of each treatment group were prepared for subsequent iTRAQ analysis and stored at $-20^{\circ} \mathrm{C}$ prior to use.

\section{Protein sample preparation and iTRAQ labelling}

Quantitative 4-plex iTRAQ proteomics analysis was performed on four independent protein samples for each treatment. Protein sample preparation and iTRAQ labeling was as previously described [25]. Briefly, the protein samples were de-salted, reduced, alkylated, and trypsin-digested according to the iTRAQ protocol [Sciex]. The resulting peptide samples were labeled with iTRAQ reagents as follows: 114: Untreated control (Cont); 115: glutamic acid treated (Glut); 116: R18 treated (R18); 117: R18 and glutamic acid treated (R18 + Glut). All labeled samples were combined to make a pooled sample. Peptides were desalted on a Strata-X $33 \mu \mathrm{M}$ polymeric reversed phase column (Phenomenex) and dissolved in a buffer containing $2 \%$ acetonitrile $0.1 \%$ formic acid before separation by High $\mathrm{pH}$ on an Agilent 1100 HPLC system using a Zorbax C18 column $(2.1 \times 150 \mathrm{~mm})$. Peptides were eluted with a linear gradient of $20 \mathrm{mM}$ ammonium formate, $2 \% \mathrm{ACN}$ to $20 \mathrm{mM}$ ammonium formate, $90 \% \mathrm{ACN}$ at $0.2 \mathrm{~mL} /$ min. The 95 fractions were concatenated into 12 fractions and dried down. Each fraction was analyzed by electrospray ionization mass spectrometry using the Shimadzu Prominence nano HPLC system [Shimadzu] coupled to a 5600 TripleTOF mass spectrometer [Sciex]. Samples were loaded onto an Agilent Zorbax 300SB-C18, $3.5 \mu \mathrm{m}$ [Agilent Technologies] and separated with a linear gradient of water/acetonitrile/0.1\% formic acid (v/v). Fourteen percent of the labeled sample was loaded on the mass spectrometer.

\section{Proteomic data analysis: qualification and quantitation} Spectral data was qualified using ProteinPilot ${ }^{\mathrm{ma}} 5.0$ software [Sciex] against the SwissProt database, utilizing the 
Rattus norvegicus (Rat) taxonomy (Version: April 2017, 7,985 sequences; https://www.uniprot.org/proteomes/ UP000002494). The False Discovery Rate (FDR) was automatically calculated by the Proteomics System Performance Evaluation Pipeline (PSPEP) feature in the ProteinPilot $^{\text {tw }}$ software (AB Sciex, Foster, CA, USA; Version 5.0.1) using the reversed version of the protein sequences contained in the search database. For quantitative protein analysis, a fold change in protein expression $> \pm 1.3$-fold with a $p<0.05$ was considered to be a 'differentially expressed protein' (DEP). Protein expression changes with R18, Glut, and R18 + Glut treatment were compared to the control (Cont). In addition, protein changes with Glut treatment were compared with R18 + Glut treatment using Cont protein expression as baseline.

\section{Proteomic data analysis: bioinformatics}

Gene ontology analysis with the 'Protein ANalysis THrough Evolutionary Relationships' (PANTHER; Version 14.0, released 2018-12-03; http://pantherdb.org/) classification system was utilized to categorize the collective DEPs in the R18, Glut, or R18 + Glut samples, relative to Cont sample, as well as Glut sample, relative to the Glut + R18 sample. These proteins were functionally categorized according to the domains of 'biological processes', 'molecular functions', and 'cellular components' [26].

Protein-protein interaction networks were identified using STRING (Version 11.0, released 2017-05-14; http://www.string-db.org/). STRING is a database of known and predicted physical and functional proteinprotein interaction, generated through computational prediction from five key databases: 'Genomic Context Predictions,' 'High-throughput Lab Experiments', '(Conserved) Co-Expression', 'Automated Textmining, and 'Previous Knowledge in Databases'. Cytoscape (Version 3.7.1) was subsequently utilized to construct and analyze the protein-protein interaction networks, and 'Cluster with overlapping Neighbourhood Expansion' (Cluster ONE; Version 14) was used for network clustering of protein-protein interactions, to identify densely connected and overlapping protein networks.

Identified DEPs were also imported into the Kyoto Encyclopedia of Genes and Genomes (KEGG) Pathway database (http://www.genome.jp/kegg/pathway.html) for analysis of common biological pathways and diseases associated with the DEPs.

\section{Statistical analysis}

Statistical analysis was conducted with the Prism 8.0 GraphPad statistical software package. Cell viability data were expressed as mean \pm S.E.M. of biological replicates, and multiple comparisons were conducted with one-way ANOVA and Bonferroni's post hoc test to assess significance, with significance taken as $p<0.05$. For Cytoscape network analysis, network cut-offs of $>3$ proteins were utilized, and a one-sided Mann-Whitney U test was used to identify significant common networks $(p<0.05)$.

\section{Results}

R18 improves cell viability in uninjured and glutamic acid-treated neuronal cells

In line with previous studies [12], R18 exhibited potent neuroprotection against glutamic excitotoxic injury in cortical neuronal cultures. In addition, as has been previously reported, cell viability was also significantly increased in neuronal cultures treated with R18 compared to control cultures (Fig. 2).

\section{Quantitative and qualitative proteomic analysis}

iTRAQ proteomic analysis detected 7,528 distinct peptide fragments with $>95 \%$ confidence, resulting in the identification of 800 proteins (minimum of $\geq 2$ matching peptide hits with $>95 \%$ confidence) consisting of a total of 140 distinct proteins (Table 1 and Additional file 1: Table S1). When compared to Cont, R18, Glut, and Glut + R18 differentially regulated 5, 95 and 14 proteins, respectively (Table 1; see Additional file 2: Table S2 for Glut + R18 DEPs). When compared to Glut, R18 + Glut differentially regulated 98 proteins (Table 1 and Additional file 2: Table S2).

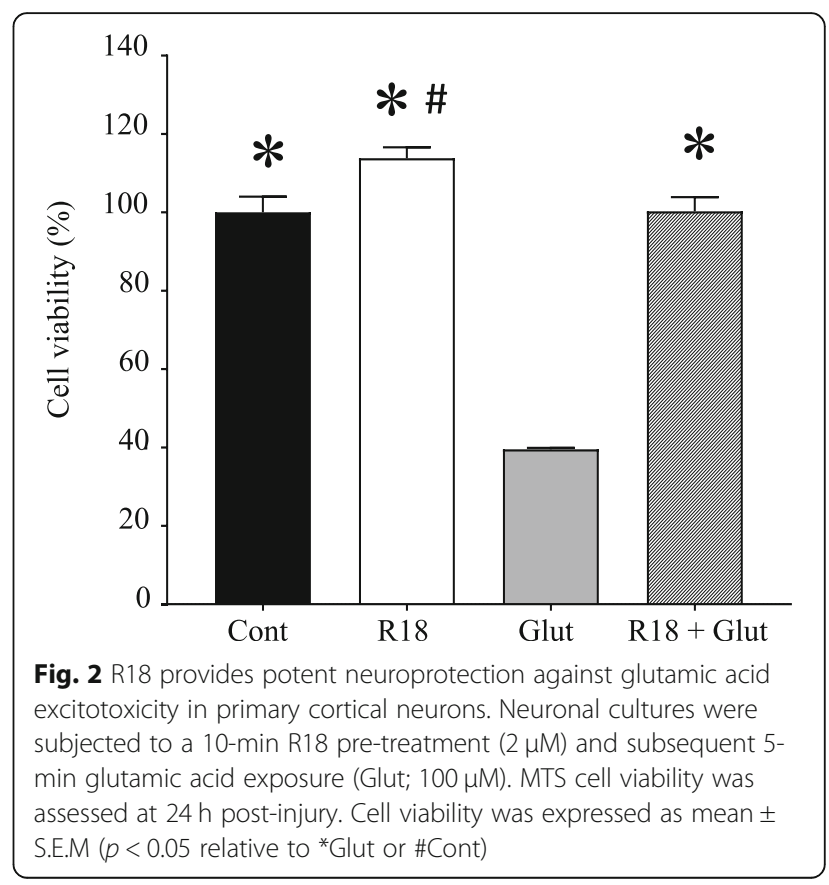


Table 1 Differentially expressed proteins identified in neurons treated with: R18 (R18), glutamic acid (Glut), or R18 and glutamic acid exposure (R18+Glut)

\begin{tabular}{|c|c|c|c|c|c|}
\hline \multirow[t]{2}{*}{ Gene name } & \multirow{2}{*}{$\begin{array}{l}\text { SwissProt } \\
\text { Accession } \\
\text { Number }\end{array}$} & \multirow[t]{2}{*}{ Protein } & \multicolumn{3}{|c|}{ Fold up-/down-regulated ${ }^{a}$} \\
\hline & & & R18 vs Cont & Glut vs Cont & R18+ Glut vs Glut \\
\hline \multicolumn{6}{|c|}{ Mitochondrial respiration/function } \\
\hline Acly & P16638 & ATP-citrate synthase & 1.076 & $-2.399^{b}$ & 1.659 \\
\hline Aco2 & Q9ER34 & Aconitate hydratase, mitochondrial & -1.028 & -3.435 & 4.285 \\
\hline Atp5a1 & P15999 & ATP synthase subunit alpha, mitochondrial & -1.472 & 1.888 & -2.421 \\
\hline Atp5b & P10719 & ATP synthase subunit beta, mitochondrial & -1.117 & 2.558 & -3.342 \\
\hline Atp5h & P31399 & ATP synthase subunit $d$, mitochondrial & 1.076 & $2.754^{b}$ & -1.836 \\
\hline Atp5o & Q06647 & ATP synthase subunit $O$, mitochondrial & 1.406 & $2.032^{\mathrm{b}}$ & -1.644 \\
\hline Cat & P04762 & Catalase & -1.555 & 1.138 & $-1.659^{b}$ \\
\hline Cox4i1 & P10888 & Cytochrome c oxidase subunit 4 isoform 1, mitochondrial & -1.259 & 2.070 & -2.704 \\
\hline Idh1 & P41562 & Isocitrate dehydrogenase [NADP] cytoplasmic & 1.066 & 1.459 & -1.486 \\
\hline Mdh2 & P04636 & Malate dehydrogenase, mitochondrial & -1.247 & 2.355 & -2.535 \\
\hline Ndufs1 & Q66HF1 & NADH-ubiquinone oxidoreductase $75 \mathrm{kDa}$ subunit, mitochondrial & 1.294 & 2.443 & -5.249 \\
\hline Uqcrc2 & P32551 & Cytochrome b-c1 complex subunit 2, mitochondrial & -1.247 & 1.888 & -2.704 \\
\hline \multicolumn{6}{|c|}{ Proteasome \& Protein synthesis } \\
\hline Asns & P49088 & Asparagine synthetase [glutamine-hydrolyzing] & 2.089 & 2.228 & $2.421^{b}$ \\
\hline Cct2 & Q5XIM9 & T-complex protein 1 subunit beta & 1.106 & -3.802 & 3.631 \\
\hline Cct3 & Q6P502 & T-complex protein 1 subunit gamma & -1.158 & -4.787 & 4.207 \\
\hline Cct4 & Q7TPB1 & T-complex protein 1 subunit delta & 1.127 & -3.944 & 3.499 \\
\hline Cct5 & Q68FQ0 & T-complex protein 1 subunit epsilon & 1.096 & -2.269 & 2.291 \\
\hline Psmc1 & P62193 & 265 protease regulatory subunit 4 & -1.419 & -22.67 & 18.197 \\
\hline \multicolumn{6}{|c|}{ Axonal growth/Neuronal differentiation/Cytoskeletal arrangement } \\
\hline Actr2 & Q5M7U6 & Actin-related protein 2 & -1.355 & -1.271 & $-1.459^{b}$ \\
\hline Ap2m1 & P84092 & AP-2 complex subunit mu & 1.271 & -5.394 & 6.855 \\
\hline Armc10 & B1WBW4 & Armadillo repeat-containing protein 10 & -1.294 & -6.667 & 2.070 \\
\hline Baiap2 & Q6GMN2 & Brain-specific angiogenesis inhibitor 1-associated protein 2 & -1.331 & -90.09 & 99.083 \\
\hline Basp1 & Q05175 & Brain acid soluble protein 1 & 1.343 & 1.614 & -1.270 \\
\hline Cntn1 & Q63198 & Contactin-1 & -1.117 & 1.977 & -1.836 \\
\hline Cttn & Q66HL2 & Src substrate cortactin & 1.117 & $-5.345^{\mathrm{b}}$ & 3.251 \\
\hline Dcx & Q9ESI7 & Neuronal migration protein doublecortin & 1.000 & -6.139 & 6.026 \\
\hline Dnm1 & P21575 & Dynamin-1 & -2.148 & -4.093 & 3.076 \\
\hline Dpys 12 & P47942 & Dihydropyrimidinase-related protein 2 & -1.225 & 1.723 & -1.690 \\
\hline Dync1h1 & P38650 & Cytoplasmic dynein 1 heavy chain 1 & -1.087 & -8.873 & 8.472 \\
\hline Fabp7 & P55051 & Fatty acid-binding protein, brain & -1.028 & $4.406^{b}$ & -4.207 \\
\hline Fyn & Q62844 & Tyrosine-protein kinase Fyn & 1.117 & -2.489 & $2.754^{\mathrm{b}}$ \\
\hline Gdi1 & P50398 & Rab GDP dissociation inhibitor alpha & -1.419 & 1.820 & -2.965 \\
\hline Gfap & P47819 & Glial fibrillary acidic protein & 1.4322 & $1.906^{\mathrm{b}}$ & -1.159 \\
\hline Kif21b & F1M5N7 & Kinesin-like protein KIF21B & -1.282 & -17.857 & 16.444 \\
\hline Krt1 & Q6IMF3 & Keratin, type II cytoskeletal & $-4.055^{b}$ & -1.236 & -6.485 \\
\hline Krt10 & Q6IFW6 & Keratin, type I cytoskeletal 10 & -2.168 & -1.722 & $-16.892^{b}$ \\
\hline Map2 & P15146 & Microtubule-associated protein 2 & 1.138 & -8.628 & 11.482 \\
\hline Map4 & Q5M7W5 & Microtubule-associated protein 4 & -2.884 & -4.488 & 4.169 \\
\hline Mapt & P19332 & Microtubule-associated protein tau & 1.077 & -7.179 & 7.379 \\
\hline
\end{tabular}


Table 1 Differentially expressed proteins identified in neurons treated with: R18 (R18), glutamic acid (Glut), or R18 and glutamic acid exposure (R18 + Glut) (Continued)

\begin{tabular}{|c|c|c|c|c|c|}
\hline \multirow[t]{2}{*}{ Gene name } & \multirow{2}{*}{$\begin{array}{l}\text { SwissProt } \\
\text { Accession } \\
\text { Number }\end{array}$} & \multirow[t]{2}{*}{ Protein } & \multicolumn{3}{|c|}{ Fold up-/down-regulated ${ }^{a}$} \\
\hline & & & R18 vs Cont & Glut vs Cont & R18+ Glut vs Glut \\
\hline Myh10 & Q9JLT0 & Myosin-10 & -1.459 & -2.466 & 2.228 \\
\hline Ncam1 & P13596 & Neural cell adhesion molecule 1 & -1.180 & 2.831 & -4.093 \\
\hline $\mathrm{Pa} 2 \mathrm{~g} 4$ & Q6AYD3 & Proliferation-associated protein 2G4 & 1.202 & -2.188 & $2.489^{b}$ \\
\hline Pak3 & Q62829 & Serine/threonine-protein kinase PAK 3 & -2.208 & -4.365 & $5.754^{b}$ \\
\hline bPebp1 & P31044 & Phosphatidylethanolamine-binding protein 1 & 1.5276 & $2.780^{\mathrm{b}}$ & -2.128 \\
\hline Rala & P63322 & Ras-related protein Ral-A & -1.236 & $2.704^{b}$ & -1.690 \\
\hline Rtn4 & Q9JK11 & Reticulon-4 & 1.107 & -2.148 & 2.679 \\
\hline Tpm4 & P09495 & Tropomyosin alpha-4 chain & -1.097 & -2.270 & $1.738^{\mathrm{b}}$ \\
\hline Tuba4a & Q5XIF6 & Tubulin alpha-4A chain & 1.086 & $-2.679^{b}$ & 2.535 \\
\hline Tubb5 & P69897 & Tubulin beta- 5 chain & -1.038 & -18.018 & 16.444 \\
\hline \multicolumn{6}{|c|}{ Vesicular/Transmembrane trafficking } \\
\hline Actn4 & Q9QXQ0 & Alpha-actinin-4 & -1.294 & $1.906^{\mathrm{b}}$ & -1.381 \\
\hline Actr1a & P85515 & Alpha-centractin & -1.738 & $-3.565^{\mathrm{b}}$ & 2.148 \\
\hline Ap2a2 & P18484 & AP-2 complex subunit alpha-2 & 1.159 & -2.582 & $3.698^{\mathrm{b}}$ \\
\hline Atp1a3 & P06687 & Sodium/potassium-transporting ATPase subunit alpha-3 & -2.128 & 1.660 & -2.355 \\
\hline Cadps & Q62717 & Calcium-dependent secretion activator 1 & -1.486 & -11.481 & 6.194 \\
\hline Camk2a & P11275 & Calcium/calmodulin-dependent protein kinase type II subunit alpha & -1.419 & -6.667 & 6.918 \\
\hline Cask & Q62915 & Peripheral plasma membrane protein CASK & 1.514 & 1.306 & $-1.888^{b}$ \\
\hline Dpysl5 & Q9JHUO & Dihydropyrimidinase-related protein 5 & -1.180 & 1.213 & $-1.459^{b}$ \\
\hline $\mathrm{Klc1}$ & P37285 & Kinesin light chain 1 & 1.107 & $-6.024^{b}$ & 5.058 \\
\hline Nsf & Q9QUL6 & Vesicle-fusing ATPase & -1.117 & -5.807 & 4.656 \\
\hline Prkar2b & P12369 & CAMP-dependent protein kinase type II-beta regulatory subunit & -1.472 & -3.105 & 1.754 \\
\hline Stx1b & P61265 & Syntaxin-1B & 1.225 & 1.600 & -1.419 \\
\hline Stxbp1 & P61765 & Syntaxin-binding protein 1 & -1.107 & 1.600 & -2.466 \\
\hline Syn 1 & P09951 & Synapsin-1 & -1.786 & $-3.597^{b}$ & 3.3113 \\
\hline \multicolumn{6}{|c|}{ ER proteostasis/Protein modification } \\
\hline Calr & P18418 & Calreticulin & 1.419 & 1.871 & -1.570 \\
\hline Ddost & Q641Y0 & Oligosaccharyl transferase $48 \mathrm{kDa}$ subunit & -1.500 & 2.466 & -2.938 \\
\hline Erp29 & P52555 & Endoplasmic reticulum resident protein 29 & -1.067 & $2.168^{\mathrm{b}}$ & -3.163 \\
\hline Hsp90aa1 & P82995 & Heat shock protein HSP 90-alpha & 1.038 & 1.282 & $-1.446^{b}$ \\
\hline Hspa5 & P06761 & 78 kDa glucose-regulated protein & 1.038 & 2.014 & -1.542 \\
\hline Hspa8 & P63018 & Heat shock cognate $71 \mathrm{kDa}$ protein & 1.259 & -2.208 & $2.559^{\mathrm{b}}$ \\
\hline Hspa9 & P48721 & Stress-70 protein, mitochondrial & 1.159 & -6.083 & 8.318 \\
\hline Hspd1 & P63039 & $60 \mathrm{kDa}$ heat shock protein, mitochondrial & 1.107 & 1.486 & -1.556 \\
\hline Pdia3 & P11598 & Protein disulfide-isomerase A3 & -1.600 & 1.614 & -1.995 \\
\hline Phb & P67779 & Prohibitin & -1.213 & 1.644 & -2.535 \\
\hline Phb2 & Q5XIH7 & Prohibitin-2 & -1.047 & 3.837 & -2.992 \\
\hline Por & P00388 & NADPH--cytochrome P450 reductase & -1.107 & -1.038 & $1.343^{b}$ \\
\hline Tcp1 & P28480 & T-complex protein 1 subunit alpha & -1.472 & $-3.597^{b}$ & 2.911 \\
\hline Uba1 & Q5U300 & Ubiquitin-like modifier-activating enzyme 1 & -1.107 & -5.105 & 4.406 \\
\hline \multicolumn{6}{|c|}{ Glycolysis \& Carbohydrate metabolism } \\
\hline Alb & P02770 & Serum albumin & -1.570 & 1.722 & -5.701 \\
\hline
\end{tabular}


Table 1 Differentially expressed proteins identified in neurons treated with: R18 (R18), glutamic acid (Glut), or R18 and glutamic acid exposure (R18 + Glut) (Continued)

\begin{tabular}{|c|c|c|c|c|c|}
\hline \multirow[t]{2}{*}{ Gene name } & \multirow{2}{*}{$\begin{array}{l}\text { SwissProt } \\
\text { Accession } \\
\text { Number }\end{array}$} & \multirow[t]{2}{*}{ Protein } & \multicolumn{3}{|c|}{ Fold up-/down-regulated ${ }^{a}$} \\
\hline & & & R18 vs Cont & Glut vs Cont & R18 + Glut vs Glut \\
\hline Aldoa & P05065 & Fructose-bisphosphate aldolase A & -1.660 & 1.629 & -2.355 \\
\hline Eno1 & P04764 & Alpha-enolase & 1.107 & 2.911 & -1.706 \\
\hline Gapdh & P04797 & Glyceraldehyde-3-phosphate dehydrogenase & -1.028 & -11.700 & 10.280 \\
\hline Gpi & Q6P6V0 & Glucose-6-phosphate isomerase & -1.318 & 1.754 & -3.435 \\
\hline$H k 1$ & P05708 & Hexokinase-1 & 1.138 & $2.051^{b}$ & -1.888 \\
\hline Ldha & P04642 & L-lactate dehydrogenase A chain & -1.786 & 1.028 & $-1.675^{b}$ \\
\hline Pkm & P11980 & Pyruvate kinase PKM & -1.009 & 1.787 & -1.941 \\
\hline Taldo1 & Q9EQS0 & Transaldolase & 1.259 & -1.837 & 2.109 \\
\hline \multicolumn{6}{|c|}{ Mitochondrial fatty acid synthesis } \\
\hline Acat1 & P17764 & Acetyl-CoA acetyltransferase, mitochondrial & 1.159 & 2.377 & -1.500 \\
\hline Bdh1 & P29147 & D-beta-hydroxybutyrate dehydrogenase, mitochondrial & -1.213 & -5.970 & 4.246 \\
\hline Fasn & P12785 & Fatty acid synthase & -1.117 & -3.311 & 2.704 \\
\hline Got2 & P00507 & Aspartate aminotransferase, mitochondrial & -1.923 & 1.213 & $-2.109^{b}$ \\
\hline \multicolumn{6}{|c|}{ Ribosome components/RNA trafficking \& processing } \\
\hline Aars & P50475 & Alanine--tRNA ligase, cytoplasmic & -1.556 & -5.495 & 4.699 \\
\hline C1qbp & O35796 & ASF/SF2-associated protein p32 & 1.213 & $1.600^{\mathrm{b}}$ & -1.888 \\
\hline$D d \times 1$ & Q641Y8 & ATP-dependent RNA helicase DDX1 & -1.148 & -11.173 & 4.286 \\
\hline Eef1a1 & P62630 & Elongation factor 1-alpha 1 & -1.225 & -5.444 & 4.529 \\
\hline Eef2 & P05197 & Elongation factor 2 & -1.202 & -4.131 & 3.048 \\
\hline Eif4a2 & Q5RKI1 & Eukaryotic initiation factor $4 \mathrm{~A}-\|$ & -1.057 & -3.945 & 3.02 \\
\hline Eif5a & Q3T1J1 & Eukaryotic translation initiation factor 5A-1 & 1.514 & -6.983 & 9.638 \\
\hline Elavl2 & Q8CH84 & ELAV-like protein 2 & -1.107 & -4.405 & $5.598^{\mathrm{b}}$ \\
\hline Hnrnpa1 & P04256 & Heterogeneous nuclear ribonucleoprotein A1 & -1.076 & -9.911 & 9.462 \\
\hline Hnrnpa2b1 & A7VJC2 & Heterogeneous nuclear ribonucleoproteins A2/B1 & 1.318 & -4.325 & 6.138 \\
\hline Hnrnpa3 & Q6URK4 & Heterogeneous nuclear ribonucleoprotein A3 & 1.191 & -3.311 & 4.920 \\
\hline Hnrnpd & Q9JJ54 & Heterogeneous nuclear ribonucleoprotein D0 & 1.202 & -5.495 & 6.252 \\
\hline Hnrnpk & P61980 & Heterogeneous nuclear ribonucleoprotein $\mathrm{K}$ & -1.057 & -8.091 & 8.872 \\
\hline Hnrnpl & F1LQ48 & Heterogeneous nuclear ribonucleoprotein $L$ & -1.028 & -2.729 & $4.207^{b}$ \\
\hline Khsrp & Q99PF5 & Far upstream element-binding protein 2 & 1.556 & -3.908 & $8.017^{b}$ \\
\hline Matr3 & P43244 & Matrin-3 & -1.500 & $-3.373^{b}$ & 3.945 \\
\hline Rpl7 & P05426 & 605 ribosomal protein $L 7$ & 1.225 & -2.109 & $2.188^{b}$ \\
\hline Rpl13 & P41123 & $60 S$ ribosomal protein $\mathrm{L} 13$ & -1.057 & -2.377 & $2.754^{\mathrm{b}}$ \\
\hline Rplp0 & P19945 & 605 acidic ribosomal protein P0 & $1.486^{\mathrm{b}}$ & -1.191 & -1.076 \\
\hline $\operatorname{Rps} 24$ & P62850 & 40 S ribosomal protein S24 & 1.854 & -5.754 & $14.06^{\mathrm{b}}$ \\
\hline Rps27 & Q71TY3 & 40 S ribosomal protein $\mathrm{S} 27$ & -1.102 & $-18.18^{b}$ & 5.058 \\
\hline Yars & Q4KM49 & Tyrosine--tRNA ligase, cytoplasmic & -1.225 & -4.656 & 3.342 \\
\hline \multicolumn{6}{|c|}{ Calcium transport and signalling } \\
\hline Vdac1 & Q9Z2L0 & Voltage-dependent anion-selective channel protein 1 & -1.419 & 2.466 & -2.938 \\
\hline Cacna2d1 & P54290 & Voltage-dependent calcium channel subunit alpha-2/delta-1 & 1.306 & 4.207 & -4.018 \\
\hline Gnaol & P59215 & Guanine nucleotide-binding protein $\mathrm{G}(\mathrm{o})$ subunit alpha & -1.148 & -5.152 & 3.802 \\
\hline Letm1 & Q5XIN6 & LETM1 and EF-hand domain-containing protein 1, mitochondrial & -3.020 & $1.459^{\mathrm{b}}$ & -1.236 \\
\hline Nudt3 & Q566C7 & Diphosphoinositol polyphosphate phosphohydrolase 1 & $1.459^{b}$ & 1.282 & 1.117 \\
\hline
\end{tabular}


Table 1 Differentially expressed proteins identified in neurons treated with: R18 (R18), glutamic acid (Glut), or R18 and glutamic acid exposure (R18+Glut) (Continued)

\begin{tabular}{llllll}
\hline Gene name & $\begin{array}{l}\text { SwissProt } \\
\text { Accession } \\
\text { Number }\end{array}$ & Protein & Fold up-/down-regulated \\
\cline { 3 - 6 } $\begin{array}{c}\text { Ywhaq } \\
\text { Miscellaneous }\end{array}$ & P68255 & 14-3-3 protein theta & -1.087 & $\mathbf{1 . 3 5 5}$ & $\mathbf{- 1 . 6 1 5}$ \\
Ak1 & P39069 & Adenylate kinase isoenzyme 1 (Cellular energy homeostasis) & 1.009 & $\mathbf{- 2 . 9 3 8}$ & $\mathbf{4 . 3 2 5}$ \\
Atic & O35567 & Bifunctional purine biosynthesis protein PURH (Purine biosynthesis) & 1.038 & 1.923 & $\mathbf{- 2 . 6 3 0 ^ { b }}$ \\
Dnm1l & O35303 & Dynamin-1-like protein (Mitochondrial fission) & -1.820 & $\mathbf{- 7 . 5 1 9 ^ { b }}$ & 5.297 \\
Hist1h4b & P62804 & Histone H4 (Transcription regulation) & 1.754 & -3.802 & $\mathbf{7 . 5 1 6 ^ { b }}$ \\
\hline
\end{tabular}

${ }^{\text {a }}$ Statistically significant values $(p<0.05)$ for fold up-/down-regulation $\geq 1.3$-fold are highlighted in bold. ${ }^{\mathrm{b}} 25$ uniquely DEPs in R18 and Glut treatment versus Cont, or R18 + Glut treatment versus Glut

Proteins regulated by $R 18$ treatment alone (R18 vs Cont) Of the five DEPs identified in the R18 sample, three were uniquely regulated (Table 1 ). Two of these proteins were upregulated: $60 \mathrm{~S}$ acidic ribosomal protein P0 (Rplp0; 1.49) and Diphosphoinositol polyphosphate phosphohydrolase 1 (Nudt3; 1.46), and one was downregulated: keratin, type II cytoskeletal (Krt1; - 4.05).

Proteins regulated by glutamic acid injury alone (glut vs Cont) Of the 95 DEPs identified in the Glut sample, 21 were uniquely regulated (Table 1 ). The greatest magnitude fold-change in a down-regulated protein was observed for brain-specific angiogenesis inhibitor 1-associated protein 2 (Baiap2; -90.09), while the greatest foldchange in an up-regulated protein was for fatty acidbinding protein, brain (Fabp7; 4.41).

\section{Proteins regulated by $R 18$ plus glutamic acid injury $(R 18+$ Glut vs Cont)}

Of the 14 DEPs identified in the R18 + Glut sample none were uniquely regulated (Additional file 2: Table S2). The greatest magnitude fold-change in an up-regulated protein was observed for UV excision repair protein RAD23 homolog B (Rad23b; 3.251), while the greatest fold-change in a down-regulated protein was for Keratin, type I cytoskeletal 10 (Krt10; - 33.333).

\section{Proteins regulated by $R 18$ plus glutamic acid injury vs glutamic acid injury alone (R18 + Glut vs glut)}

Of the 98 DEPs identified after R18+Glut treatment (R18 + Glut vs Glut), 73 of the proteins were also regulated by R18 and/or Glut treatments alone, and 25 were uniquely regulated (Table 1 ; uniquely regulated proteins indicated by *). In addition, R18 treatment reversed the up- or down-regulation of all 73 DEPs (Table 1, Fig. 3). Of the 25 uniquely regulated proteins, the greatest magnitude fold-change in protein expression observed was with Brain-specific angiogenesis inhibitor 1-associated protein 2 (Baiap2; - 99.08).

\section{Functional categorization of differentially regulated proteins (DEPs)}

For further functional characterization of DEPs we focused on protein changes in the R18 and R18+Glut treatments groups as we were most interested in the effects of R18 on proteins regulated in uninjured and injured neurons. PANTHER Gene Ontology analysis was utilized to categorize the DEPs regulated by R18 alone ( 5 proteins; R18 vs Cont), and the DEPs regulated by R18 + Glut treatment (73 proteins; R18 + Glut vs Glut) according to 'cellular component' (Fig. 4a and d) 'biological process' (Fig. 4b and e), and 'molecular function' (Fig. 4c and f) (Full data provided in Additional file 3: Table S3).

The 5 DEPs regulated by R18 treatment included proteins located in the nucleus and ribosomes which catalyze purine nucleotide catabolic activity (e.g. Nudt3), and modulate rRNA binding (e.g. Rplp0). Other proteins regulated by $\mathrm{R} 18$ are involved in intracellular ion trafficking (e.g. Atp1a3) and cytoskeletal structure (e.g. Krt1) (Table 1).

The 73 DEPs regulated by $\mathrm{R} 18+$ Glut treatment included proteins involved in mitochondrial respiration and function (e.g. Aco2 and Atp5a1), proteasomal regulation and protein synthesis (e.g. Psmc1 and Cct3), proteostasis/protein modification in the endoplasmic reticulum (e.g. Hspa9 and Uba1), and RNA trafficking/ processing (e.g. Eif5a and Hnrnpa1), as well as cytoskeletal rearrangement and axonal growth (e.g. Map2 and Dcx) and vesicular/membrane trafficking (e.g. Atp1a3 and Camk2a). Significant changes of key neuronal proteins are summarized in the schematic detailed in Fig. 5 (full data available in Additional file 2: Table S2 and Additional file 3: Table S3).

\section{Protein-protein interaction network analysis of DEPs regulated by $\mathrm{R} 18$ in uninjured and glutamic acid injured neurons}

STRING analysis was used to identify potential proteinprotein interactions across the 5 DEPs regulated by R18 


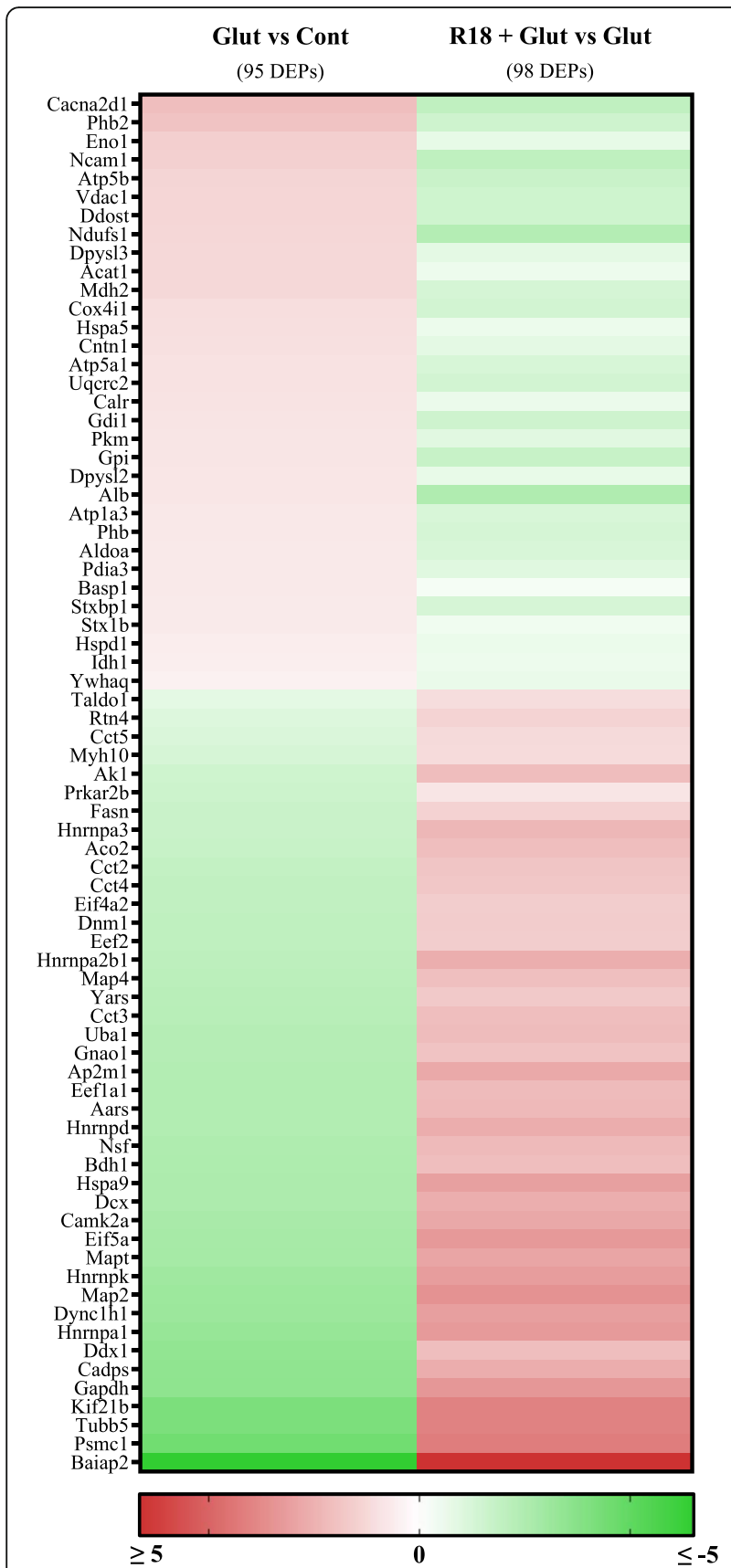

Fig. 3 Heatmap of differentially expressed proteins (DEPs) regulated by R18 vs Cont, Glut vs Cont, or R18 + Glut vs Glut. Protein expression changes are shown as log(2) of fold-change

treatment, and the 73 DEPs regulated by Glut and R18 + Glut. No significant protein-protein interactions were identified for the 5 DEPs regulated by R18 treatment (R18 vs Cont) (Fig. 6a). Two hundred and twenty-two nodes representing direct and indirect protein-protein interactions were identified for the 73 DEPs regulated by $\mathrm{R} 18+$ Glut treatment $(\mathrm{R} 18+$ Glut vs Glut) (Fig. 6b).
ClusterONE network analysis of the 222 nodes revealed that the protein-protein interactions could be grouped into eight clusters representing distinct biological functional entities (Fig. 7; boxed proteins). The clusters were classified as 'Mitochondrial respiration' (55 nodes), 'Proteasome and Protein synthesis' (43 nodes), 'Axonal growth \& neuronal differentiation' (11 nodes), 'Transmembrane trafficking' (10 nodes), 'Endoplasmic reticulum proteostasis' (8 nodes), 'Glycolysis and carbohydrate metabolism' (7 nodes), 'RNA trafficking and processing' (4 nodes), and 'Mitochondrial fatty acid synthesis' ( 4 nodes) (Full data provided in Additional file 4: Table S4).

\section{KEGG pathway analysis of 73 shared proteins}

KEGG pathway analysis to determine the biological pathways and diseases associated with 222 proteinprotein interactions identified pathways pertaining to proteostasis ('Proteasome'; 34 of 46 proteins), energy metabolism ('Oxidative phosphorylation'; 52 of 130 proteins), and neurotransmission ('Synaptic vesicle cycle'; 14 of 60 proteins), and 'Retrograde endocannabinoid signaling'; 34 of 144 proteins) (Fig. 8; full data in Additional file 5: Table S5). In addition, KEGG analysis revealed that the protein-protein interactions were associated with the neurodegenerative disorders Parkinson's disease (PD; 52 of 134 proteins), Alzheimer's disease ( $\mathrm{AD} ; 47$ of 164 proteins), and Huntington's disease (HD; 50 of 181 proteins).

\section{Discussion}

In recent years, CARPs have emerged as a novel class of potential neuroprotective therapeutics for a broad range of acute brain injuries and chronic neurodegenerative disorders. These CARPs include short-chained polyarginine peptides $[11,13,27]$, SS-peptides [28, 29], APOE-derived peptides [27, 30], and TAT-fused peptides, including TAT-NR2B9c (NA-1) and JNK1-TAT $[11,31]$. Such CARPs have been shown to exert their neuroprotective action through a variety of targets, which include structural and functional preservation of mitochondria [32], reduced ROS generation [33], inhibition of protein aggregation [34], modulation of glutamate or calcium ion receptors (excitotoxicity/calcium influx) [35], and activation of pro-survival signaling $[36,37]$. Given the diverse biochemical and cellular effects CARPs can exert on cells, it is likely that other cytoprotective processes are also involved, which have yet to be fully elucidated. To this end, the present study is the first to employ an iTRAQ proteomics approach to gain insight into protein expression changes after polyarginine-18 (R18) treatment of uninjured neuronal cultures and neuronal cultures subjected to glutamic acid excitotoxic injury. 


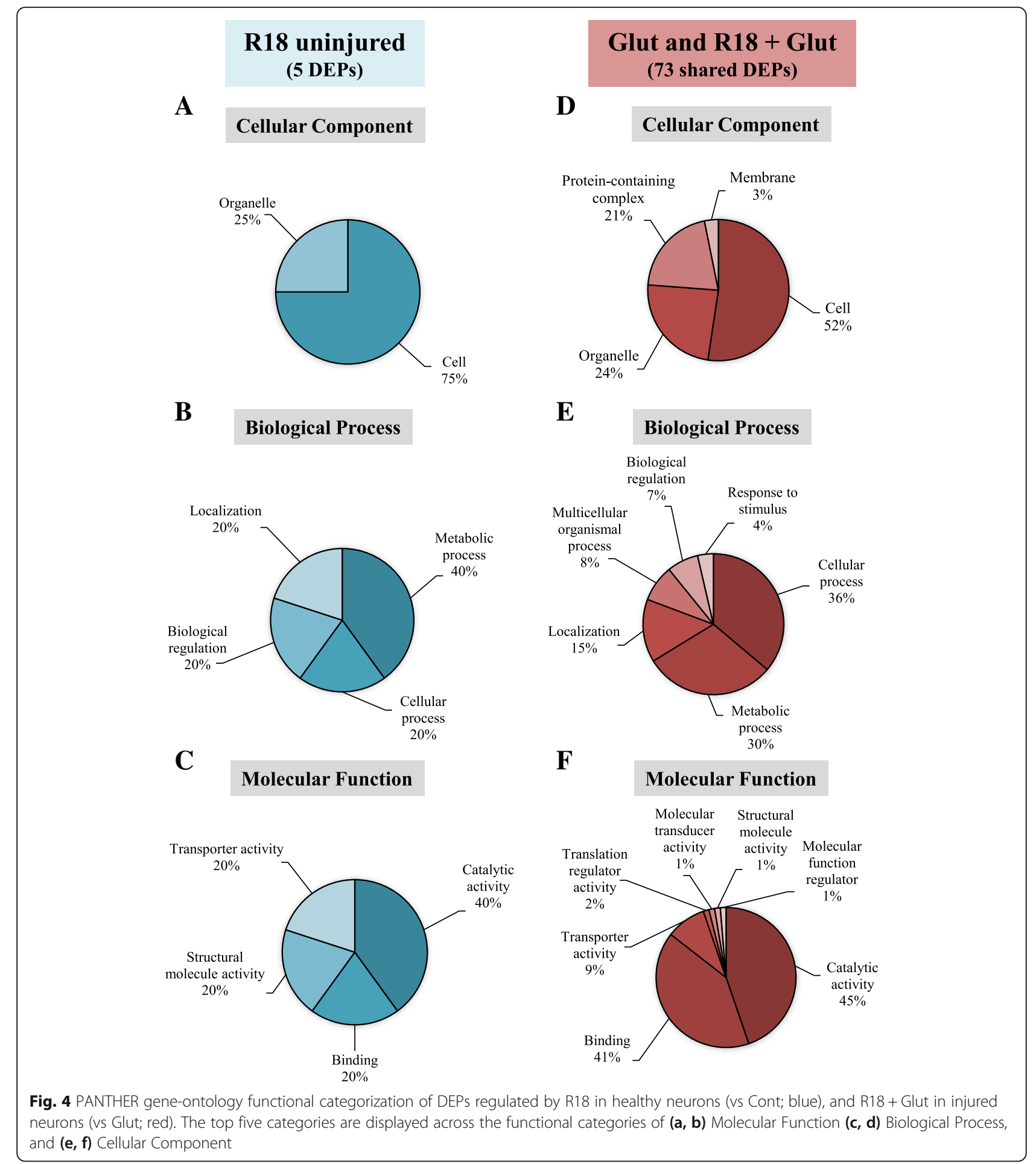

The effects of R18 treatment on uninjured neurons

Proteomics analysis of neuronal cultures 24-h after a 10-min exposure to R18 identified 5 DEPs. The small number of detected protein expression changes was surprising given that CARPs can induce a variety of biological effects on cells [38]. However, it is likely that the small number of proteins detected was in part due to the $24-\mathrm{h}$ post-R18 treatment time point used to analyze protein expression changes, as majority of the protein changes elicited by R18 treatment may potentially occur within the first few hours, and as such, may no longer have been detectable or did 


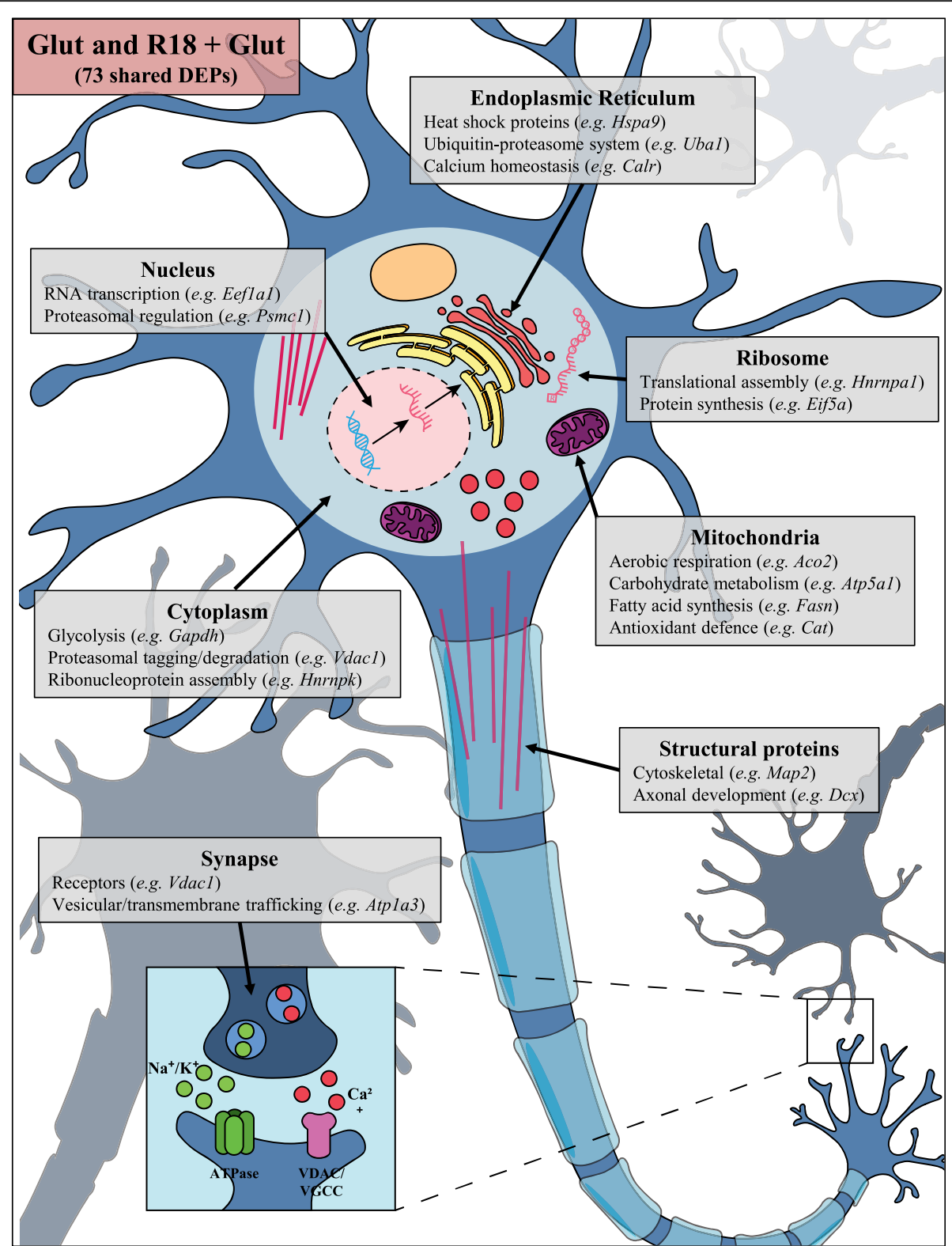

Fig. 5 Schematic representation of representative shared neuronal proteins regulated by glutamic acid excitotoxicity (Glut) and R18 + Glut, based on location and function. Comprehensive protein changes are detailed in Table 1

not fit the requirements for classification of a DEP (e.g. $\pm>1.3$ fold change) by $24 \mathrm{~h}$.

The proteins that were identified as being affected by R18 were largely associated with protein synthesis and transmembrane protein and cationic ion transport, and did not significantly map onto KEGG pathways, suggesting that the R18 peptide does not exert long-term biological effects in uninjured neurons. This is in line with the proposed notion that neuroprotective agents should preferentially interact with and/or modulate cellular targets activated following pathological events to minimize the chance of offtarget side effects. Such protective agents are deemed 'pathologically-activated' therapeutics, which are thought to have a particularly useful application in neurological disorders, as brain tissue is especially susceptible to drug-induced disruptions and unwanted drug side-effects [38, 39]. However, to provide a more comprehensive assessment of the biological effects of R18 on uninjured neurons, future studies should examine protein expression at earlier time points. 
A

\section{R18 uninjured}

(5 DEPs)

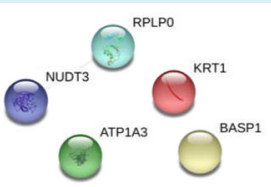

B
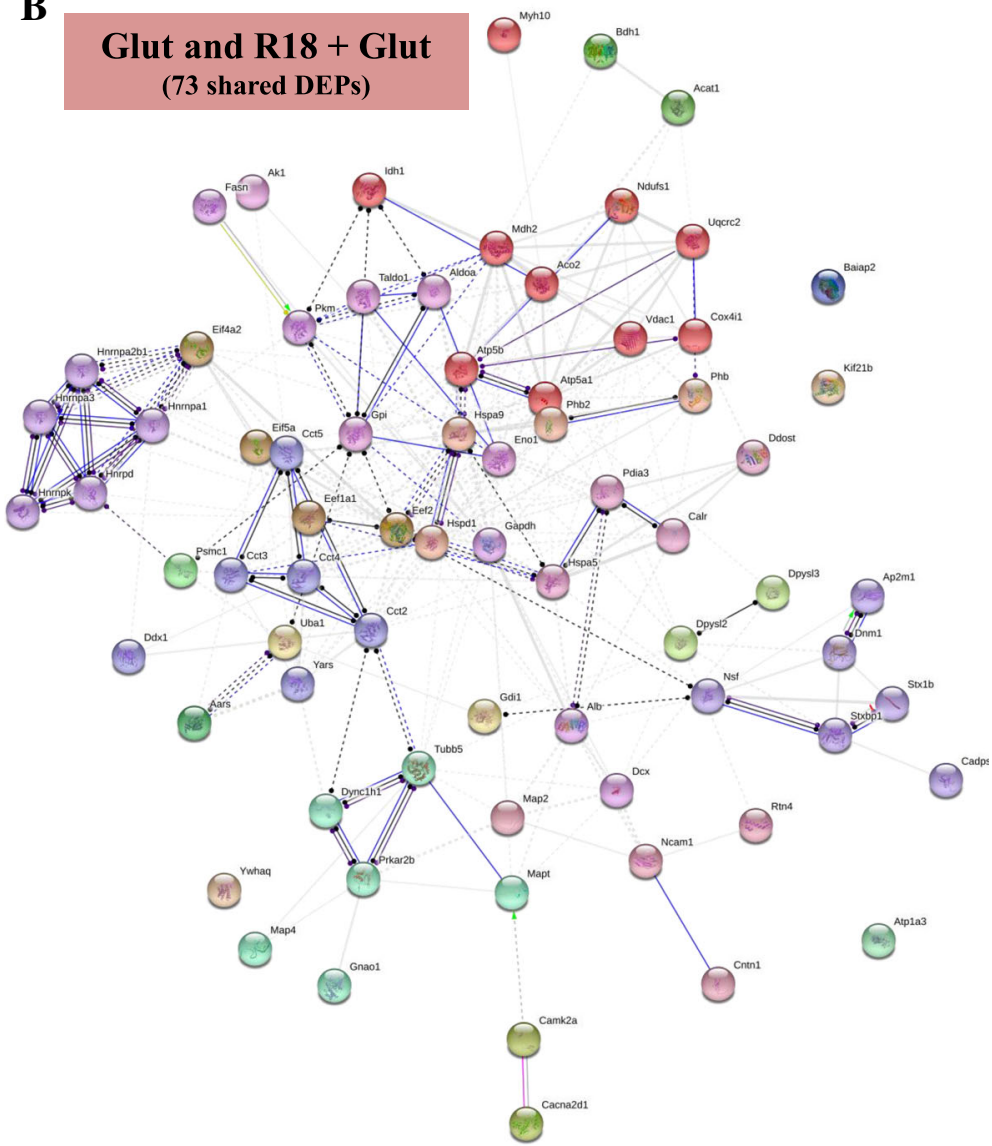

Fig. 6 Enriched STRING PPI network analysis of DEPs regulated by a. R18 treatment in healthy neurons (vs Cont), and b. DEPs commonly regulated by Glut and R18 + Glut (vs Glut), demonstrating molecular actions of direct and indirect protein-protein interactions between significantly regulated proteins. STRING parameters were set to high confidence $(0.700)$, with only query proteins shown

\section{R18 treatment reduces glutamic acid-induced changes in} protein expression

An important finding of this study was the ability of R18 treatment to reverse the majority $(74.5 \% ; 73$ of 98) of the protein changes induced by glutamic acid excitotoxicity, and thereby preserve the protein expression profiles of cortical neurons post-insult (Table 1; Additional file 4: Table S4). Further analysis revealed that these protein changes underpin key cellular functions, such as mitochondrial respiration and energy production, proteostasis, neuronal transmembrane trafficking, and RNA processing, which are dysregulated by excitotoxicity. Moreover, KEGG analysis of protein-protein interactions indicated predominant involvement of pathways pertaining to the proteasome and oxidative phosphorylation, which also represent two central biological processes underpinning aspects of neurodegenerative pathophysiology. This likely contributed to the identification of enriched protein-protein interactions pertaining to Parkinson's disease, Alzheimer's disease and Huntington's disease.

Severe and/or prolonged disruptions in the ubiquitinproteasome system have been implicated in both acute 




Fig. 7 Cytoscape ClusterONE analysis of enriched STRING protein-protein interaction network of shared DEPs regulated by both Glut and R18 + Glut. Cytoscape ClusterONE analysis was used to group protein clusters based on their involvement in 'Mitochondrial respiration', 'Axonal growth and neuronal differentiation', 'Transmembrane trafficking', 'Endoplasmic reticulum proteostasis', 'Glycolysis and carbohydrate metabolism', 'Mitochondrial fatty acid synthesis', or 'RNA trafficking and processing.' Clusters represent statistical significance cut-offs of $p<0.05$, and empty nodes represent proteins that do not share statistically significant functions with other proteins

(ischaemic stroke, TBI) and chronic (AD, PD, motor neuron disease) neurological disorders $[39,40]$. Previous studies have shown that CARPs exhibit proteasomal modulatory activity and could potentially conserve protein expression profiles through inhibition of injury-induced proteasomal protein degradation. For example, the arginine-rich PR-11 (H-RRRPRPPYLPRPRPPPFFPPRLPPRIPPGFPPRFPPR FP-OH; net charge +11 ) and PR-39 (H-RRRPRPPY LPR-OH; net charge +5 ) peptides attenuate inflammation induced by ischaemia-reperfusion injury through inhibition of proteasomal degradation of I $\mathrm{B} \alpha$; a NFkB inhibitory protein $[41,42]$. Taken together, it appears CARPs can influence the function of the proteasome, and thereby exert neuroprotective benefits during times of cellular stress.

Proteomic analysis also revealed that R18 preserved protein expression profiles pertaining to mitochondrial bioenergetics and structural integrity. Mitochondria are central mediators of intracellular calcium signaling events during excitotoxicity, and as such, are considered the "judge, jury, and executioner" of the cell [31, 43].
During excitotoxic injury, mitochondria act as a buffer for toxic intracellular calcium accumulation, however excessive mitochondrial calcium uptake can disrupt their structural and functional integrity, resulting in the release of pro-death signaling proteins from the mitochondrial inter-membrane space $[44,45]$. Therefore, the ability of R18 treatment to attenuate excitotoxicityinduced protein changes underlying loss of mitochondrial integrity, provides evidence that the peptide helps preserve the function of the organelle in times of cellular stress. In line with the ability of CARPs to maintain mitochondrial function and energy generation, in this and previous studies R18 was demonstrated to increase MTS metabolism in uninjured neurons and in neurons after exposure to glutamic acid [14].

Bioinformatic analysis of the DEPs identified in the present study largely focused on the 73 proteins up- or down-regulated by glutamic acid excitotoxic injury. However, it is important to note that 25 other DEPs were also identified to be uniquely regulated by combined R18 + Glut treatment, which may represent additional proteins influenced by R18 and associated with 


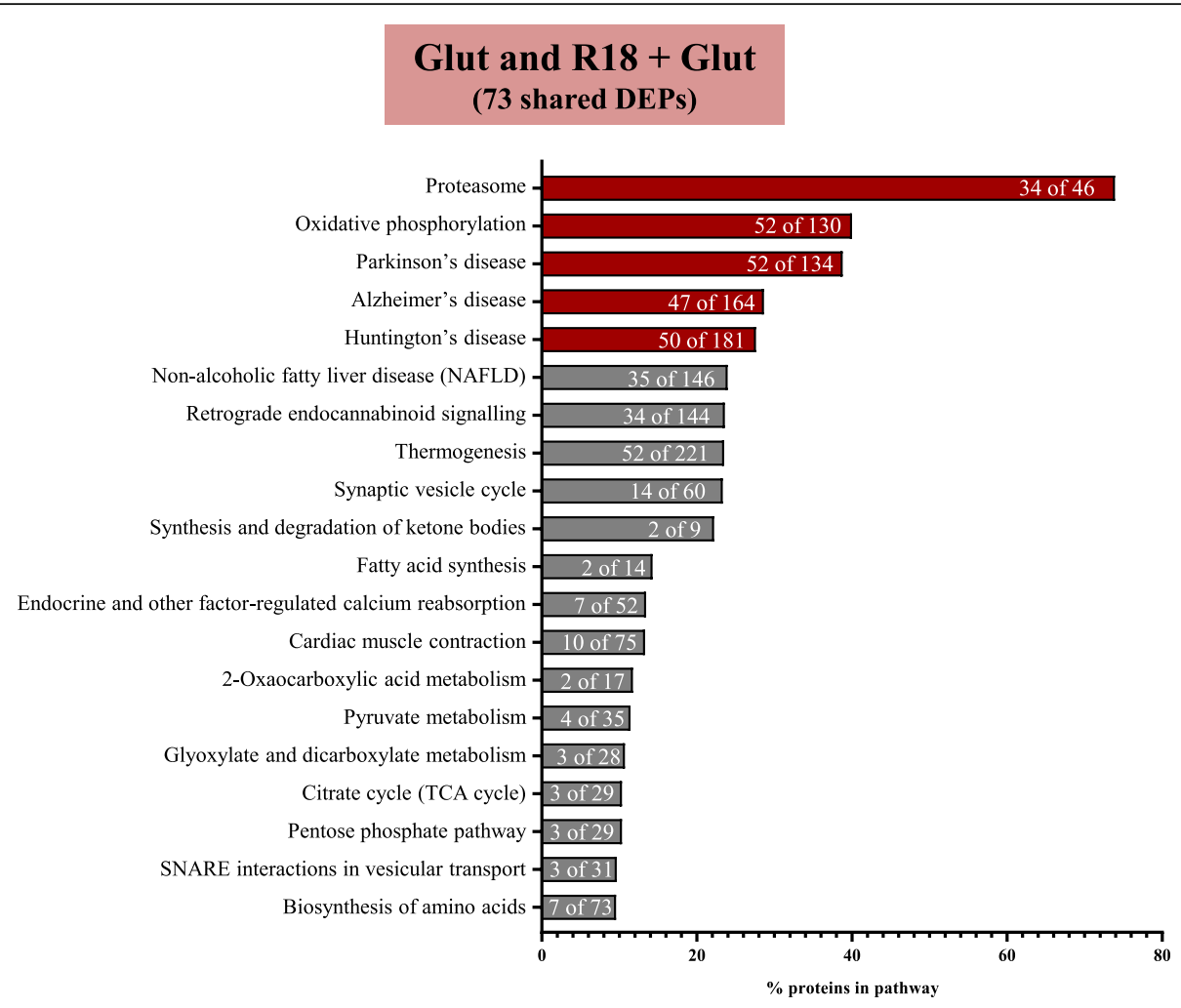

Fig. 8 Enriched KEGG pathway analysis of shared DEPs common to both Glut and R18 + Glut (vs Glut), demonstrating the top 20 pathways. Shown above is the percentage of proteins mapped to the respective significantly regulated pathways, with the fraction of regulated proteins mapping onto the total number of proteins in each pathway provided in white. The top 5 pathways are outlined in red

neuroprotection. Alternatively, these proteins could reflect non-specific changes in protein expression unrelated to neuroprotection.

\section{Limitations and future directions}

The proteomics methodology used in this study does not provide insight into other forms of protein modification, such as post-translational changes (e.g. phosphorylation, acetylation, and glycosylation), which may influence protein functions important for neuroprotection. In addition, only a 24-h timepoint was examined and therefore it would also be of interest to examine protein expression changes, as well as post-translational modifications at earlier timepoints after R18 treatment. Further studies are also required to confirm if the DEPs and the biochemical and disease pathways influenced by R18 treatment after glutamic acid excitotoxicity in vitro are also affected by the peptide in animal models of acute brain injury (e.g. stroke, TBI) and chronic neurodegenerative disorders (AD, $\mathrm{PD})$.

\section{Conclusion}

This exploratory study has demonstrated for the first time that the poly-arginine peptide R18 exerts significant effects in attenuating the protein expression changes associated with neuronal excitotoxicity in vitro, while inducing minimal changes in uninjured neurons. Collectively, our findings indicate that the neuroprotective effects of R18 following excitotoxicity are associated predominantly with preservation of neuronal proteostasis, together with positive effects on mitochondrial and proteasomal function. The findings of this study provide further evidence supporting the role of poly-arginine peptides as a potential neuroprotective therapeutic for both acute and chronic neurodegenerative disorders.

\section{Additional files}

Additional file 1: Table S1. Summary of LC-MS/MS spectral data analysis. Summary of LC-MS/MS spectral data analysis with ProteinPilot ${ }^{\text {TM }} 5.0$ Software [Sciex] using the SwissProt database (Version April 2017; 7,985 sequences) against Rattus norvegicus (Rat) taxonomy, using the reversed version of the protein sequences contained in the search database. FDR was automatically calculated with the Proteomics System Performance Evaluation Pipeline (PSPEP) feature in the ProteinPilot ${ }^{T M}$ software. (DOCX $17 \mathrm{~kb}$ )

Additional file 2: Table S2. Full iTRAQ proteomics data. Full iTRAQ proteomics data showing relative fold changes in protein expression and corresponding $p$-values. (DOCX $54 \mathrm{~kb}$ )

Additional file 3: Table S3. PANTHER gene-ontology functional categorization. PANTHER gene-ontology functional categorization of DEPs significantly regulated by R18 treatment alone (R18 vs Cont), glutamic acid exposure (Glut vs Cont), and R18 pre-treatment with glutamic acid 
exposure (R18 + Glut vs Glut). Note: proteins may have multiple functions, and as such, the total number of proteins in each category may be greater than the sum of DEPs across each treatment group. (DOCX $49 \mathrm{~kb}$ )

Additional file 4: Table S4. Cytoscape quantitative analysis. Cytoscape quantitative analysis of STRING data cluster strength for 73 shared DEPS across Glut and R18 + Glut treatment groups. (DOCX 56 kb)

Additional file 5: Table S5. Quantitative data and full gene list of KEGG pathway analysis. Quantitative data and full gene list of KEGG pathway analysis of 73 shared DEPs across Glut and R18 + Glut treatment groups, with details provided on term ID, overserved gene count vs. background gene count, and FDR. (DOCX $17 \mathrm{~kb})$

\section{Abbreviations}

AD: Alzheimer's disease; ALS: Amyotrophic lateral sclerosis; Cont: 'No treatment' group; DEP: Differentially expressed proteins; Glut: 'Glutamic acid excitotoxic injury' treatment group; HD: Huntington's disease; LC-MS/ MS: Liquid chromatography-tandem mass spectrometry; PD: Parkinson's disease; R18 + Glut: 'R18-treatment and glutamic acid injury' treatment group; R18: Poly-arginine-18 peptide

\section{Acknowledgements}

ITRAQ proteomic labelling and analysis was conducted with the help of Proteomics International Laboratories LTD, Australia.

\section{Authors' contributions}

Sample preparation, testing, and collection conducted by GM. iTRAQ protein labelling and LC-MS/MS analysed by Proteomics International Australia Pty Ltd. Bioinformatics analysed and interpreted by GM. RA, FM, and BM were major contributors to the manuscript. Minor edits were provided by NK. All authors read and approved the final manuscript.

\section{Funding}

This study was funded in part by a University Postgraduate Award (UPA) from the University of Notre Dame, Australia. Funding support was also provided by Mr. Torsten Ketelsen and the Perron Institute Fundraising Committee

\section{Availability of data and materials}

All data generated or analysed during this study are included in this published article (and its Suppl. information files).

\section{Ethics approval and consent to participate}

Approval for the use of E18 Sprague-Dawley rat embryos for isolation of cortical tissue was obtained by the University of Western Australia Animal Ethics Committee (RA/3/100/1432).

\section{Consent for publication}

Not applicable.

\section{Competing interests}

B.P. Meloni and N.W. Knuckey are named inventors of several patent applications (Provisional Patents: 2013904197; 30/ 10/2013 and 2014902319; 17/6/2014 and PCT/ AU2014/050326; 30/10/2104) regarding the use of arginine-rich peptides as neuroprotective agents. The other authors declare they have no conflict of interest.

\section{Author details}

${ }^{1}$ Centre for Neuromuscular and Neurological Disorders, The University of Western Australia, Nedlands, Australia. ${ }^{2}$ Department of Neurosurgery, Sir Charles Gairdner Hospital, QEll Medical Centre, Nedlands, Western Australia, Australia. ${ }^{3}$ Perron Institute for Neurological and Translational Sciences, QEIl Medical Centre, Ground Floor, RR Block, 8 Verdun St, Nedlands, Western Australia 6009, Australia. ${ }^{4}$ School of Heath Sciences and Institute for Health Research, The University Notre Dame, Fremantle, Western Australia, Australia.
Received: 6 June 2019 Accepted: 1 July 2019

Published online: 17 July 2019

\section{References}

1. Xing C, Arai K, Lo EH, Hommel M. Pathophysiologic cascades in ischemic stroke. Int J Stroke. 2012. https://doi.org/10.1111/j.1747-4949.2012.00839.x.

2. Platt SR. The role of glutamate in central nervous system health and disease - a review. Vet J. 2007. https://doi.org/10.1016/j.tvjl.2005.11.007.

3. Talantova M, Sanz-Blasco S, Zhang X, Xia P, Akhtar MW, Okamoto S -i, et al. $A \beta$ induces astrocytic glutamate release, extrasynaptic NMDA receptor activation, and synaptic loss. Proc Natl Acad Sci. 2013. https://doi.org/10.1 073/pnas.1306832110.

4. De Felice FG, Velasco PT, Lambert MP, Viola K, Fernandez SJ, Ferreira ST, et al. $\mathrm{A} \beta$ oligomers induce neuronal oxidative stress through an N-methyl-Daspartate receptor-dependent mechanism that is blocked by the Alzheimer drug memantine. J Biol Chem. 2007. https://doi.org/10.1074/jbc.M607483200.

5. Zeron MM, Hansson $\mathrm{O}$, Chen $\mathrm{N}$, Wellington $\mathrm{CL}$, Leavitt BR, Brundin $\mathrm{P}$, et al. Increased sensitivity to $\mathrm{N}$-methyl-D-aspartate receptor-mediated excitotoxicity in a mouse model of Huntington's disease. Neuron. 2002. https://doi.org/10.1016/S0896-6273(02)00615-3.

6. Shehadeh J, Fernandes HB, Zeron Mullins MM, Graham RK, Leavitt BR, Hayden MR, et al. Striatal neuronal apoptosis is preferentially enhanced by NMDA receptor activation in YAC transgenic mouse model of Huntington disease. Neurobiol Dis. 2006. https://doi.org/10.1016/j.nbd.2005.08.001.

7. Helton TD, Otsuka T, Lee M-C, Mu Y, Ehlers MD. Pruning and loss of excitatory synapses by the parkin ubiquitin ligase. Proc Natl Acad Sci. 2008. https://doi.org/10.1073/pnas.0802280105.

8. Zádori D, Klivényi P, Plangár I, Toldi J, Vécsei L. Endogenous neuroprotection in chronic neurodegenerative disorders: with particular regard to the kynurenines. J Cell Mol Med. 2011. https://doi.org/10.1111/j.15 82-4934.2010.01237.x.

9. Carriedo SG, Yin HZ, Weiss JH. Motor neurons are selectively vulnerable to AMPA/kainate receptor-mediated injury in vitro. J Neurosci. 1996. https:// doi.org/10.1523/jneurosci.2021-10.2010.

10. Van Damme P, Van den Bosch L, Van Houtte E, Callewaert G, Robberecht W. GluR2-dependent properties of AMPA receptors determine the selective vulnerability of motor neurons to excitotoxicity. J Neurophysiol. 2002. https://doi.org/10.1152/jn.00163.2002.

11. Meloni BP, Craig AJ, Milech N, Hopkins RM, Watt PM, Knuckey NW. The neuroprotective efficacy of cell-penetrating peptides TAT, penetratin, Arg-9, and Pep-1 in glutamic acid, kainic acid, and in vitro ischemia injury models using primary cortical neuronal cultures. Cell Mol Neurobiol. 2014. https:// doi.org/10.1007/s10571-013-9999-3.

12. Meloni BP, Brookes LM, Clark WW, Cross JL, Edwards AB, Anderton RS, et al. Poly-arginine and arginine-rich peptides are neuroprotective in stroke models. J Cereb Blood Flow Metab. 2015. https://doi.org/10.1038/jcbfm.2015.11.

13. Meloni BP, Milani D, Cross JL, Clark WW, Edwards AB, Anderton RS, et al. Assessment of the neuroprotective effects of arginine-rich protamine peptides, poly-arginine peptides (R12-cyclic, R22) and arginine-tryptophancontaining peptides following in vitro excitotoxicity and/or permanent middle cerebral artery occlusion in rats. NeuroMolecular Med. 2017. https:// doi.org/10.1007/s12017-017-8441-2.

14. Milani D, Bakeberg MC, Cross JL, Clark WW, Anderton RS, Blacker DJ, et al. Comparison of neuroprotective efficacy of poly-arginine R18 and R18D (Denantiomer) peptides following permanent middle cerebral artery occlusion in the Wistar rat and in vitro toxicity studies. PLoS One. 2018. https://doi. org/10.1371/journal.pone.0193884.

15. Milani D, Cross JL, Anderton RS, Blacker DJ, Knuckey NW, Meloni BP. Neuroprotective efficacy of poly-arginine R18 and NA-1 (TAT-NR2B9C) peptides following transient middle cerebral artery occlusion in the rat. Neurosci Res. 2017. https://doi.org/10.1016/j.neures.2016.09.002.

16. Milani D, Cross JL, Anderton RS, Blacker DJ, Knuckey NW, Meloni BP. Delayed 2h post-stroke administration of R18 and NA-1 (TAT-NR2B9c) peptides after permanent and/or transient middle cerebral artery occlusion in the rat. Brain Res Bull. 2017. https://doi.org/10.1016/j.brainresbull.2017.09.012.

17. Milani D, Clark VW, Cross JL, Anderton RS, Knuckey NW, Meloni BP. Poly-arginine peptides reduce infarct volume in a permanent middle cerebral artery rat stroke model. BMC Neurosci. 2016. https://doi.org/1 0.1186/s12868-016-0253-z.

18. Milani D, Knuckey NW, Anderton RS, Cross UL, Meloni BP. The R18 polyarginine peptide is more effective than the TAT-NR2B9C (NA-1) peptide when 
administered 60 minutes after permanent middle cerebral artery occlusion in the rat. Stroke Res Treat. 2016. https://doi.org/10.1155/2016/2372710.

19. Edwards AB, Cross JL, Anderton RS, Knuckey NW, Meloni BP. Poly-arginine R18 and R18D (D-enantiomer) peptides reduce infarct volume and improves behavioural outcomes following perinatal hypoxic-ischaemic encephalopathy in the P7 rat. Mol Brain. 2018. https://doi.org/10.1186/s13 041-018-0352-0.

20. Chiu LS, Anderton RS, Cross JL, Clark WW, Edwards AB, Knuckey NW, et al. Assessment of R18, COG1410, and APP96-110 in excitotoxicity and traumatic brain injury. Transl Neurosci. 2017. https://doi.org/10.1515/ tnsci-2017-0021.

21. Chiu LS, Anderton RS, Cross JL, Clark WW, Knuckey NW, Meloni BP. Polyarginine peptide $\mathrm{R} 18 \mathrm{D}$ reduces neuroinflammation and functional deficits following traumatic brain injury in the long-Evans rat. Int J Pept Res Ther. 2019. https://doi.org/10.1007/s10989-018-09799-8.

22. MacDougall G, Anderton RS, Edwards AB, Knuckey NW, Meloni BP. The neuroprotective peptide poly-arginine-12 (R12) reduces cell surface levels of NMDA NR2B receptor subunit in cortical neurons; investigation into the involvement of endocytic mechanisms. J Mol Neurosci. 2017. https://doi. org/10.1007/s12031-016-0861-1.

23. Szeto HH. Mitochondria-targeted cytoprotective peptides for ischemiareperfusion injury. Antioxid Redox Signal. 2007. https://doi.org/10.1089/ ars.2007.1892

24. Meloni BP, Majda BT, Knuckey NW. Establishment of neuronal in vitro models of ischemia in 96-well microtiter strip-plates that result in acute, progressive and delayed neuronal death. Neuroscience. 2001. https://doi. org/10.1016/S0306-4522(01)00396-7.

25. Casey T, Solomon PS, Bringans S, Tan KC, Oliver RP, Lipscombe R. Quantitative proteomic analysis of G-protein signalling in Stagonospora nodorum using isobaric tags for relative and absolute quantification. Proteomics. 2010. https://doi.org/10.1002/pmic.200900474.

26. Mi H, Poudel S, Muruganujan A, Casagrande JT, Thomas PD. PANTHER version 10: expanded protein families and functions, and analysis tools. Nucleic Acids Res. 2016. https://doi.org/10.1093/nar/gkv1194.

27. Meloni BP, Milani D, Edwards AB, Anderton RS, O'Hare Doig RL, Fitzgerald $M$, et al. Neuroprotective peptides fused to arginine-rich cell penetrating peptides: neuroprotective mechanism likely mediated by peptide endocytic properties. Pharmacol Ther. 2015. https://doi.org/10.1 016/j.pharmthera.2015.06.002.

28. Zhao K, Zhao GM, Wu D, Soong Y, Birk AV, Schiller PW, et al. Cell-permeable peptide antioxidants targeted to inner mitochondrial membrane inhibit mitochondrial swelling, oxidative cell death, and reperfusion injury. J Biol Chem. 2004. https://doi.org/10.1074/jbc.M402999200.

29. Szeto HH, Liu S, Soong Y, Wu D, Darrah SF, Cheng F-Y, et al. Mitochondriatargeted peptide accelerates ATP recovery and reduces ischemic kidney injury. J Am Soc Nephrol. 2011. https://doi.org/10.1681/ASN.2010080808.

30. Aono M, Bennett ER, Kim KS, Lynch JR, Myers J, Pearlstein RD, et al. Protective effect of apolipoprotein E-mimetic peptides on -methyl-Daspartate excitotoxicity in primary rat neuronal-glial cell cultures. Neuroscience. 2003. https://doi.org/10.1016/S0306-4522(02)00709-1.

31. MacDougall G, Anderton RS, Mastaglia FL, Knuckey NW, Meloni BP. Mitochondria and neuroprotection in stroke: cationic arginine-rich peptides (CARPs) as a novel class of mitochondria-targeted neuroprotective therapeutics. Neurobiol Dis. 2019. https://doi.org/10.1016/j.nbd.2018.09.010.

32. Birk AV, Liu S, Soong $Y$, Mills W, Singh P, Warren JD, et al. The mitochondrial-targeted compound SS-31 re-energizes ischemic mitochondria by interacting with cardiolipin. J Am Soc Nephrol. 2013. https://doi.org/10.1681/ASN.2012121216.

33. Petri S, Kiaei M, Damiano M, Hiller A, Wille E, Manfredi G, et al. Cellpermeable peptide antioxidants as a novel therapeutic approach in a mouse model of amyotrophic lateral sclerosis. J Neurochem. 2006. https:// doi.org/10.1111/j.1471-4159.2006.04018.x.

34. Gibson TJ, Murphy RM. Design of peptidyl compounds that affect $\beta$-amyloid aggregation: importance of surface tension and context. Biochemistry. 2005. https://doi.org/10.1021/bi050225s.

35. Fan J, Cowan CM, Zhang LYJ, Hayden MR, Raymond LA. Interaction of postsynaptic density protein-95 with NMDA receptors influences excitotoxicity in the yeast artificial chromosome mouse model of huntington's disease. J Neurosci. 2009. https://doi.org/10.1523/JNEUROSCI.2491-09.2009.

36. Cook DR, Gleichman AJ, Cross SA, Doshi S, Ho W, Jordan-Sciutto KL, et al. NMDA receptor modulation by the neuropeptide apelin: implications for excitotoxic injury. J Neurochem. 2011. https://doi.org/10.1111/j.1471-4159.2 011.07383.x.

37. O'Donnell LA, Agrawal A, Sabnekar P, Dichter MA, Lynch DR, Kolson DL. Apelin, an endogenous neuronal peptide, protects hippocampal neurons against excitotoxic injury. J Neurochem. 2007. https://doi.org/10.1111/j.14 71-4159.2007.04645.x

38. Brugnano J, Ward BC, Panitch A. Cell penetrating peptides can exert biological activity: a review. Biomol Concepts. 2010. https://doi.org/1 0.1515/bmc.2010.016.

39. Ross CA, Poirier MA. Protein aggregation and neurodegenerative disease. Nat Med. 2004. https://doi.org/10.1038/nm1066.

40. Ciechanover A, Brundin P. The ubiquitin proteasome system in neurodegenerative diseases: sometimes the chicken, sometimes the egg. Neuron. 2003. https://doi.org/10.1016/S0896-6273(03)00606-8.

41. Bao J, Sato K, Li M, Gao Y, Abid R, Aird W, et al. PR-39 and PR-11 peptides inhibit ischemia-reperfusion injury by blocking proteasome-mediated I kappa B alpha degradation. Am J Physiol Heart Circ Physiol. 2001. https:// doi.org/10.1152/ajpheart.2001.281.6.H2612.

42. Anbanandam A, Albarado DC, Tirziu DC, Simons M, Veeraraghavan S. Molecular basis for proline- and arginine-rich peptide inhibition of proteasome. J Mol Biol. 2008. https://doi.org/10.1016/j.jmb.2008.09.021.

43. Yang JL, Mukda S, Der CS. Diverse roles of mitochondria in ischemic stroke. Redox Biol. 2018. https://doi.org/10.1016/j.redox.2018.03.002.

44. Stout AK, Raphael HM, Kanterewicz BI, Klann E, Reynolds IJ. Glutamateinduced neuron death requires mitochondrial calcium uptake. Nat Neurosci. 1998. https://doi.org/10.1038/1577.

45. Castilho RF, Ward MW, Nicholls DG. Oxidative stress, mitochondrial function, and acute glutamate excitotoxicity in cultured cerebellar granule cells. J Neurochem. 1999. https://doi.org/10.1046/j.1471-4159.1999.721394.x.

\section{Publisher's Note}

Springer Nature remains neutral with regard to jurisdictional claims in published maps and institutional affiliations.

\section{Ready to submit your research? Choose BMC and benefit from:}

- fast, convenient online submission

- thorough peer review by experienced researchers in your field

- rapid publication on acceptance

- support for research data, including large and complex data types

- gold Open Access which fosters wider collaboration and increased citations

- maximum visibility for your research: over $100 \mathrm{M}$ website views per year

At $\mathrm{BMC}$, research is always in progress.

Learn more biomedcentral.com/submissions 